\title{
Effect of Liquid Injection Intensity on Preferential Flow and Its Characteristics by Soil Sensors
}

\author{
Shiliang Zhang, ${ }^{1,2^{*}}$ Xiaosheng Liu, ${ }^{3}$ and Guoqin Sun $^{4}$ \\ ${ }^{1}$ School of Information and Electromechanical Engineering, Ningde Normal University, Ningde 352100, China \\ ${ }^{2}$ School of Resources and Environment Engineering, Jiangxi University of Science and Technology, \\ Ganzhou, Jiangxi 341000, China \\ ${ }^{3}$ School of Architectural and Surveying \& Mapping Engineering, Jiangxi University of Science and Technology, \\ Ganzhou, Jiangxi 341000, China \\ ${ }^{4}$ Pingnan County Rare Earth Development Co., Ltd., Ningde, Fujian 352100, China
}

(Received December 31, 2020; accepted March 22, 2021)

Keywords: preferential flow, rare-earth ore, preferential channel, liquid injection intensity

Preferential flow is common in soil with preferential channels and greatly affects soil water infiltration. Although previous studies have made great progress in clarifying preferential flow, there has been little investigation of the effect of the preferential channel on preferential flow, and it is necessary to understand how precipitation intensity affects preferential flow. In this study, to examine the preferential flow characteristics of rare-earth ions by the dyeing method and moisture sensors and to determine the influence of the development degree of the preferential channel in a rare-earth ore on the characteristics of preferential flow with different liquid injection intensities using Brilliant Blue FCF, indoor and outdoor experiments were carried out to monitor the development of preferential flow in real time and compare the development degree of soil preferential flow with different liquid injection intensities. The results show that the more developed the preferential channel, the more developed the preferential flow, and that the influence of the liquid injection intensity on the preferential flow rate and its degree of enhancement increases with increasing soil preferential channel development. However, when the injection intensity is low, preferential flow cannot be formed even in soil with abundant macropores. When studying the influence of liquid injection intensity on preferential flow, the influence of the development degree of the preferential channel is considered. The results of this study enrich the theory of preferential flow, enabling the evaluation of agricultural water use, soil pollution migration, groundwater pollution risk assessment, and clarification of landslide mechanisms.

\section{Introduction}

Preferential flow refers to the phenomenon that soil water flows through preferential flow channels such as large pores, cracks, wormholes, and crop roots, bypassing most of the soil matrix and quickly passing through the soil medium. The phenomenon of preferential flow is widespread and has a significant impact on the process of soil water infiltration. Preferential

*Corresponding author: e-mail: shiliangzh@163.com

https://doi.org/10.18494/SAM.2021.3279 
channels can accelerate the infiltration of soil water into deep soil and even aquifers, reduce the efficiency of soil water use, and increase the risk of pesticides, fertilizers, and other pollutants entering groundwater. ${ }^{(1)}$

A preferential channel is the main reason for preferential flow and its larger flow capacity is why the infiltration rate of preferential flow is larger than that of the soil matrix.(2) The occurrence of preferential flow is closely related to the existence of fissures, cracks, and holes in the soil structure. Numerous domestic and international research results have shown that preferential flow exists extensively in soils rather than as special cases. ${ }^{(3,4)}$ With increasing initial water content of the soil, the initial infiltration rate decreases, the time required for steady infiltration decreases, and runoff occurs in advance. ${ }^{(5,6)}$ However, there is still uncertainty in the cumulative infiltration of soil moisture and the migration of the wet front. Wu and Wang ${ }^{(7)}$ and Zeng et al. ${ }^{(8)}$ respectively studied the influences of initial soil water content on the soil vertical line source and brackish water infiltration and considered that the amount of cumulative infiltration decreased with increasing initial water content. By studying the influence of injection on the distribution characteristics of soil water transport, Cheng et al. ${ }^{\left({ }^{9}\right)}$ found that the accumulated soil filtration increased with increasing soil water content. Zhang and Shao ${ }^{(10)}$ concluded that the velocity of the wetting front increased with increasing initial water content, for which $\mathrm{Wu}$ and $\mathrm{Wang}^{(7)}$ took the opposite opinion. Zeng et al. ${ }^{(8)}$ considered that both Yangling soil and sand loess had a peak water content and that the transport of the wetting front had a parabolic relation with the water content. There have been numerous studies on the channel distribution of the preferential flow of rare-earth ores, but there is still no clear definition of the categories of preferential flow. In particular, for in situ leaching, the influences of the injection intensity and saturation degree on preferential flow still remain to be defined. There are various methods of studying preferential flow. ${ }^{(11,12)}$ Among them, the dyeing trace method can conveniently verify the existence of preferential flow. ${ }^{(13,14)}$ This method involves dissolving a dye that can stain the water in a rare-earth ore, and can be used to simulate rainfall. The region through which the dyeing water penetrates fully is clearly dyed, allowing the preferential flow to be analyzed and determined with image analysis software. Because the dyeing trace method is easy, feasible, and low-cost, and the dyeing path is also obvious, it has been extensively adopted to study preferential flow. In this study, the dyeing trace method, Photoshop CS5.0 professional cartographic software, and Image-Pro Plus 6.0 are adopted to study the spatial distribution characteristics of the preferential flow of an ion-type rare-earth ore. In situ and outdoor experiments are also carried out to study the relationship between liquid injection intensity and preferential flow in a soil column with abundant macropores and to explore the influence of the liquid injection intensity of the rare earth on preferential flow, giving us a more comprehensive understanding of preferential flow and providing a reference for further research.

\section{Processing Tools}

An RS-WS-N01-TR-1 (Shandong Renke Measurement and Control Technology Co., Ltd.) soil moisture sensor with a range of $0-100 \%$ and a measurement accuracy of $\pm 3 \%$ was used in the experiment. The measurement area with a diameter of $7 \mathrm{~cm}$ and a height of $7 \mathrm{~cm}$ is centered on 
the central probe. Figure 1 shows the soil moisture sensor. The data of the moisture sensor is directly transmitted to the host, the sampling rate is set to once every $5 \mathrm{~min}$, and the changes in the volumetric moisture content of the ore body during the liquid injection process are automatically recorded.

\section{Characteristics of Preferential Flow of Ionic Rare Earths}

Domestic and international researchers have developed some dyeing image evaluation indexes in their study of the preferential flow of rare-earth ores to evaluate the development degree of preferential flow, including the dyeing area ratio, preferential flow rate, depth of matrix flow, and maximum dyeing depth. ${ }^{(15-17)}$

Two sets of outdoor experiments were designed. Two injection dyeing trace experiments on injection holes 1 and 2 were conducted on ion-type rare-earth ore from Jiangxi Province. To prevent mutual interference between the two injection hole tests, the distance between the injection holes was greater than $5 \mathrm{~m}$. Five hundred liters of Brilliant Blue FCF solution with a concentration of $4 \mathrm{~g} / \mathrm{L}$ was prepared for trace filtration. Three days later, after the dye had completely permeated the samples, six profiles were excavated vertically along the lengthwise direction of each injection hole at an equal distance $(20 \mathrm{~cm})$. The depth of the excavated profile was $85 \mathrm{~cm}$. A Canon 500D digital camera with 13 megapixels was used to take images of the dyed rare-earth ore in the vertical direction, assisted by a standard grayscale RHS color chart. It can be seen from Fig. 2 that the maximum dyeing depths of the matrix flow corresponding to injection holes 1 and 2 are 60.5 and $46 \mathrm{~mm}$, the maximum dyeing area ratios are 79.83 and $80.03 \%$, and the maximum percentage areas of the preferential flow relative to the entire dyeing region are 29.91 and $65.30 \%$, respectively. By comparing injection holes 1 and 2, it was found that there is no significant relationship between the dyeing image index of the profile and the profile spacing and that the curves vary with the soil behavior, grain composition, soil mass density, and the nature of the flow. With increasing dyeing area ratio, the matrix flow depth and the dyeing depth also increase, which demonstrates that the dyeing area ratio, matrix flow depth, and the dyeing depth are positively correlated. With increasing preferential flow ratio, the dyeing

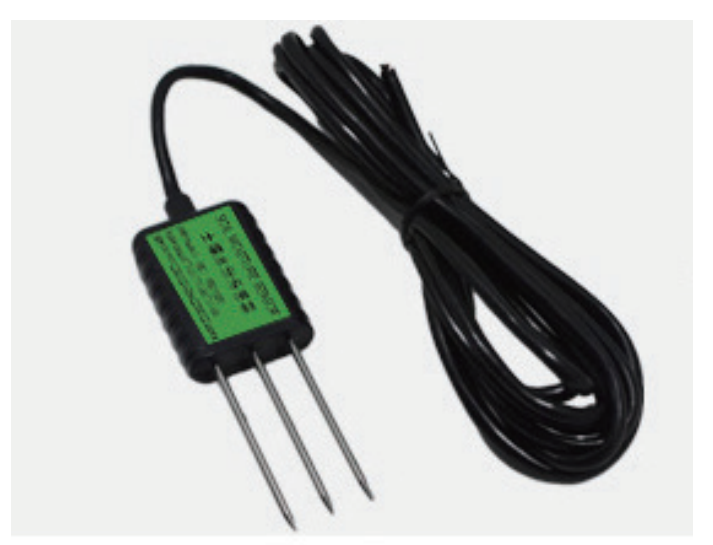

Fig. 1. (Color online) Soil moisture sensor. 


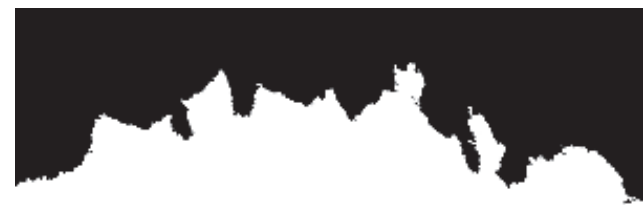

(a)

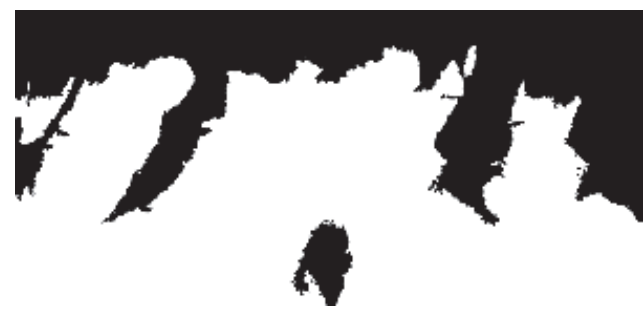

(c)

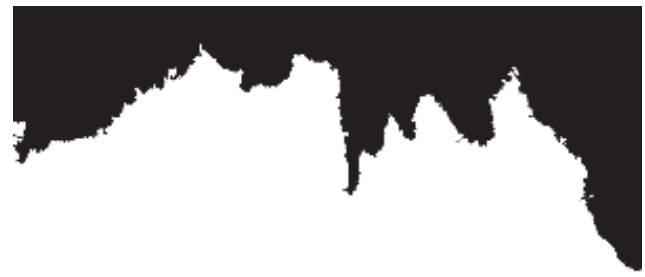

(e)

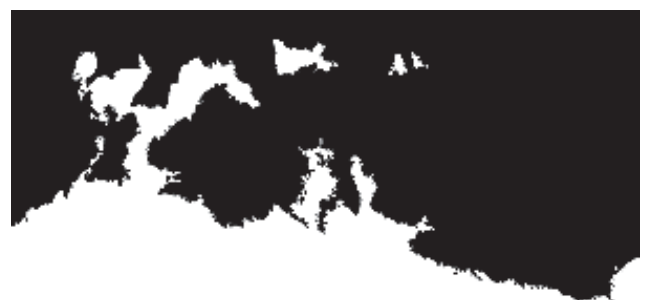

(b)

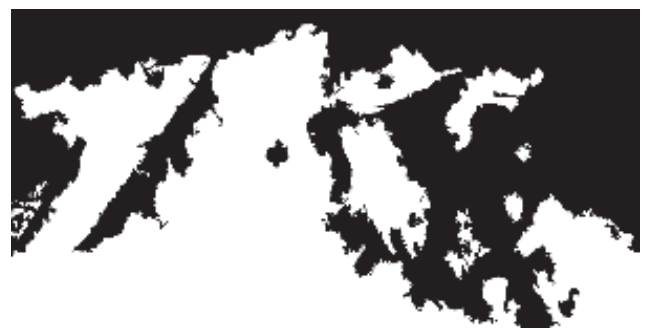

(d)

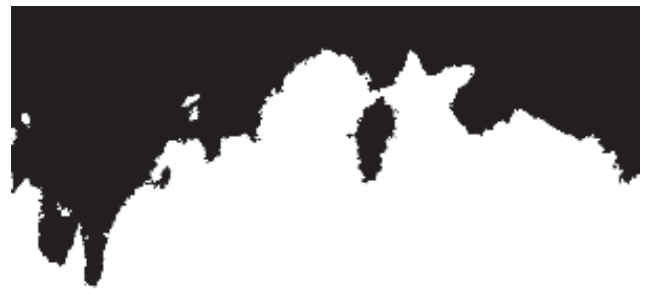

(f)

Fig. 2. Spatial distribution characteristics of preferential flow region. (a) First section of injection hole. $(\omega=19.78)$ (b) Second section of injection hole. $(\omega=23.12)$ (c) Third section of injection hole. $(\omega=24.27)$ (d) Fourth section of injection hole. $(\omega=24.75)$ (e) Fifth section of injection hole. $(\omega=21.93)$ (f) Sixth section of injection hole. $(\omega=18.06)$

area ratio, matrix flow depth, and dyeing depth decrease, i.e., the preferential flow has a negative correlation with the dyeing area ratio, matrix flow depth, and dyeing depth.

The dyeing profiles of the rare-earth ore were processed with Photoshop CS5.0 and ImagePro Plus 6.0, and the structures of the preferential flow of the ion-type rare-earth ore and the spatial distribution of the preferential flow channels were extracted. ${ }^{(18,19)}$ Using injection hole 1 as an example, the distribution of the preferential flow of all profiles is shown in Fig. 2.

In the 2D profiles in Fig. 2, white and black respectively correspond to the undyed and dyed regions, respectively, and the lengths of the columns in the 3D profiles are dyeing intensities (long columns for high intensity and short columns for low intensity). The surface of the rareearth ore is dyed uniformly and the colorant spreads by reticulate diffusion and infiltrates quickly, bypassing the matrix and forming a clear preferential flow channel. The ore is dyed more uniformly at a depth of $0-10 \mathrm{~cm}$ below the surface than at greater depths, and the water in the rare-earth ore starts to flow along the preferential flow channel. The preferential flow is 
clearest in the soil layer between 40 and $60 \mathrm{~cm}$ and the maximum dyeing depth is $84 \mathrm{~cm}$. Preferential flows exist in both injection holes. The major preferential flow types are macropore flow, finger flow, and funnel flow. In the first profile of the rare-earth ore of injection hole 1, macropore flow clearly appears with little finger flow; however, the development degree of the pores and the infiltration of the colorant slow down with increasing depth, and the dyeing depth reaches $49 \mathrm{~cm}$. In the second profile, dyeing is intermittent, which may be due to the inability of water to bypass the hard-to-pass rare-earth ore regions. In the third profile, there are many macropore flows in the shallow region of the rare-earth ore. However, the development degree of the void differs, the flow speed in the middle void is clearly larger than that on both sides, and a bifurcated flow appears in the infiltration. Many soil layers with different rare-earth ore infiltrations are found in the rare-earth ore, whose preferential flow channel distribution also varies. However, the rare-earth ore preferential flow is abundant in the fourth profile. There are many effective voids with considerably different shapes, and even funnel flow can be found. The flow in this direction is not even and is sometimes discontinuous. Circular and fast penetrating characteristics are clearly observed in the dyeing path, which are favorable for diffusion and absorption. The preferential flow distribution is complicated. In the fifth and sixth profiles, it is easy for preferential flow to develop near the soil surface, and the rare-earth ore texture and dying are even. The preferential flows are mainly finger flows with a relatively even speed of advance, and the deepest finger flow is $57.8 \mathrm{~cm}$. In other words, the dyeing area ratio follows the "strong-weak-stronger-weak-none" law with increasing depth of the rare-earth ore. The dyeing area ratio increases instantaneously in the middle layer of the rare-earth ore and then decreases gradually. These phenomena show that the preferential flows are unsteady and random. Although the dyeing area fraction is generally represented as "strong-weak-stronger-weak-none" with increasing depth of the rare-earth ore, it was found from a single profile that the dyeing area fraction increases with increasing depth of the rare-earth ore in some areas, which suggests that the water flow can bypass the rare-earth ore region where it cannot easily pass to diffuse downward continuously.

\section{Effect of Liquid Injection Intensity on Preferential Flow}

\subsection{Indoor experiments}

In the experiments, the column height was $65 \mathrm{~cm}$, the outer diameter was $11 \mathrm{~cm}$, and the inner diameter was $10 \mathrm{~cm}$. The upper part of the columns was equipped with an inlet and an overflow, while the bottom was equipped with a permeable stone as the outlet, ${ }^{(20)}$ whose radius was $5 \mathrm{~cm}$ and thickness was $2 \mathrm{~mm}$. The prepared soil sample was evenly filled as 12 layers (each with $5 \mathrm{~cm}$ thickness). Before loading, a piece of filter paper was placed on the permeable stone at the bottom of the column to prevent soil outflow. The column was filled to a height of $60 \mathrm{~cm}$, with the soil in the top $3 \mathrm{~cm}$ of the column excavated. After loading, a piece of filter paper was placed on top of the soil. There were two artificial preferential flow areas in the column. A filled artificial preferential flow cylinder with a $2 \mathrm{~cm}$ outer diameter and a $30 \mathrm{~cm}$ height was placed $20 \mathrm{~cm}$ away from the bottom of the soil column in the tube. There were two sets of artificial 
preferential flow zones. At a distance of $20 \mathrm{~cm}$ from the bottom column, two artificial preferential flow cylinder zones were established. The preferential flow was filled with a mineral soil with a particle size in the range of $0.5-1.0 \mathrm{~mm}$, so that the permeability was about three times that of the outer soil (the permeability coefficient of the outer soil column was 0.0207 $\mathrm{m} / \mathrm{d}$ and the permeability of the artificial preferential flow zone was $0.0582 \mathrm{~m} / \mathrm{d}$ ). However, the water content and void ratio were the same as those of the surrounding soil. A schematic of the cross section of the column is shown in Fig. 3, and a schematic of the vertical section of the column is shown in Fig. 4.

To study the influence of the injection intensity on the preferential flow of rare earths, different injection methods with a constant water head of $5 \mathrm{~cm}$ and no head were used for the same soil column. To study whether there is a relationship between the preferential flow of rare earths and the distribution of water content, we used small test tubes on a section $5 \mathrm{~cm}$ from the top of the column and took soil samples of about half the test tube at three different positions along a radius on the cross section, i.e., at the center and 2 and $4 \mathrm{~cm}$ from the center, as shown by red dots in Fig. 3. Because the column is $60 \mathrm{~cm}$ high, 11 sections and 55 samples can be obtained from each column. The moisture content was measured by a drying method, and the obtained distributions of the moisture content are shown in Fig. 5.

It can be seen that the water content in Fig. 5(a) is mainly distributed in the non-preferential flow area; because of the two preferential flow areas provided in the column, the horizontal distribution is different from the vertical distribution. The horizontal distribution is mainly distributed in the middle area with $X$ values of $25-30 \mathrm{~cm}$, and the vertical distribution is wide and uniform. It can be seen that owing to the existence of the preferential flow, the distribution of moisture is extremely uneven. No head can be observed in Fig. 5(b), and even though there are two preferential flow areas inside the soil column, preferential flow cannot be formed and the water distribution is relatively uniform, indicating that column leaching without a head cannot develop a preferential flow. We conclude that the higher the infiltration intensity, the greater the preferential flow in the soil, and the higher the initial water content in the soil, the more abundant the preferential flow generated, but they are not directly proportional. When the infiltration intensity is very low, preferential flow will hardly occur in the soil.

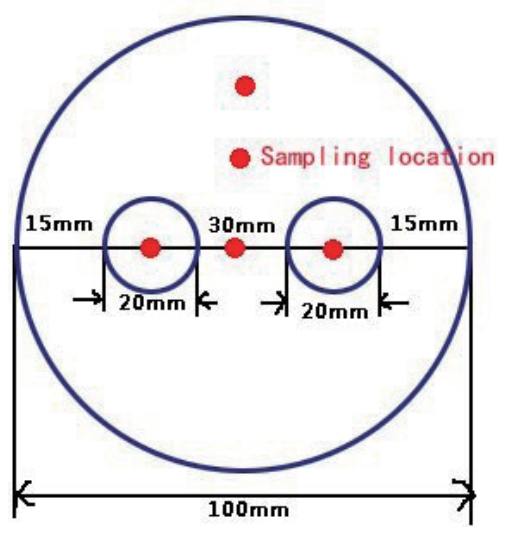

Fig. 3. (Color online) Cross section of the column.

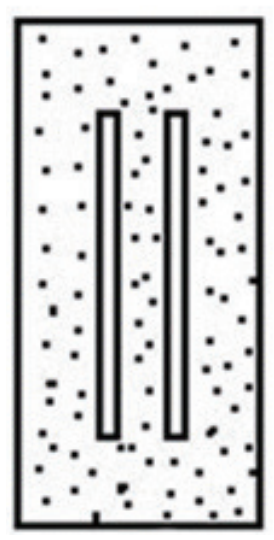

Fig. 4. Vertical section of the column. 


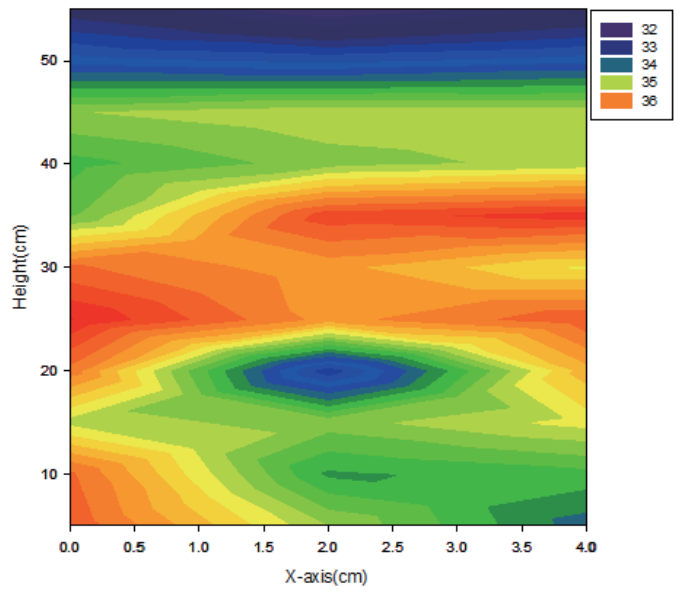

(a)

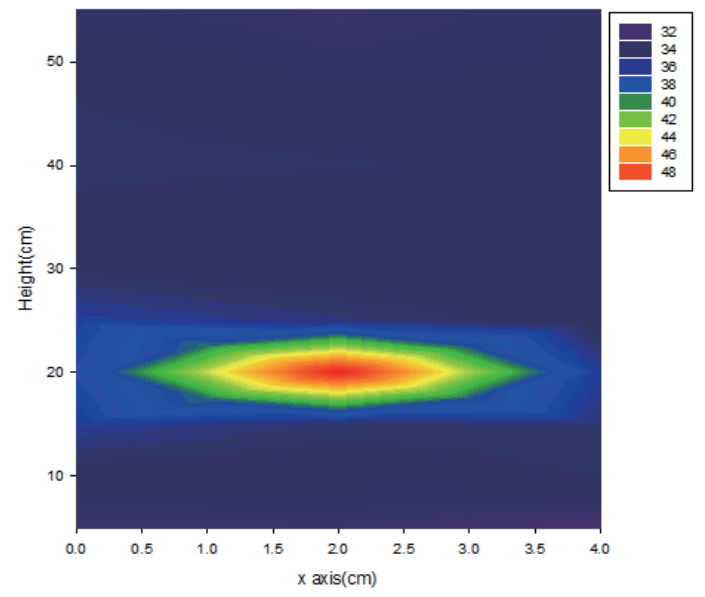

(b)

Fig. 5. (Color online) Distribution cloud maps of moisture content. (a) Water head $=5 \mathrm{~cm}$. (b) Water head $=0 \mathrm{~cm}$.

\subsection{Outdoor experiments}

In the test area, a Luoyang spatula was used to drill four injection holes with a depth of $2 \mathrm{~m}$ and a diameter of $18 \mathrm{~cm}$. A $50 \mathrm{~mm}$ polyvinyl chloride (PVC) pipe was inserted into each injection hole to the bottom of the hole. The space between the PVC pipe and the wall of the injection hole was filled with firewood to prevent the hole wall from collapsing, and a regular pattern of small holes was made in the lower half of the PVC pipe so that water could flow out of the pipe. Around each injection hole, six holes were distributed at a certain distance for embedding moisture sensors. A total of 50 moisture sensors were embedded around each injection hole to record the change in the volumetric water content of the ore body during the injection process. Among them, the liquid injection intensities of liquid injection holes Nos. 1-4 were $3,2.4,1.8$, and $1.2 \mathrm{~m}^{3} / \mathrm{d}$, respectively. A digital liquid level transmitter was used to monitor the depth of water in the injection hole 3 to 5 times a day.

As soon as the injection started, the moisture sensors began monitoring the water content of the rare-earth ore at all measuring points over repeated intervals of $3 \mathrm{~min}$, and the saturation of each measuring point was obtained accurately after the received data were calibrated. The saturation at all measuring points was processed in the form of a cloud picture (see Fig. 6). The origin of the coordinates is the center of the injection holes, the horizontal axis represents the location where the moisture sensor is embedded, and the vertical axis represents the moisture content.

It can be seen from Fig. 6 that the saturation distribution patterns of the four groups are considerably different. The preferential flow with an injection intensity of $3.0 \mathrm{~m}^{3} / \mathrm{d}$ is clearly higher than that with an injection intensity of $1.2 \mathrm{~m}^{3} / \mathrm{d}$. When the infiltration is basically stable, there is only a small saturation region surrounding the injection hole, while most of the regions are non-saturated regions with different saturations, which decrease gradually with increasing distance between the injection holes. The preferential flow increases with increasing injection 


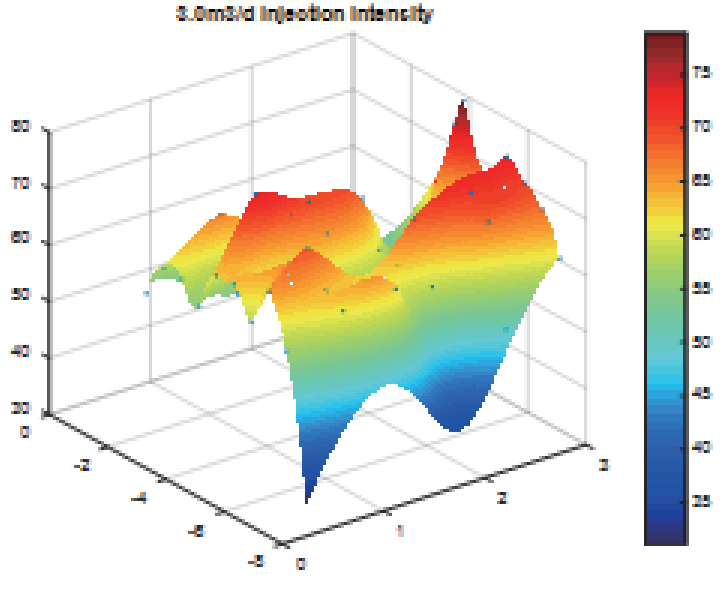

(a)

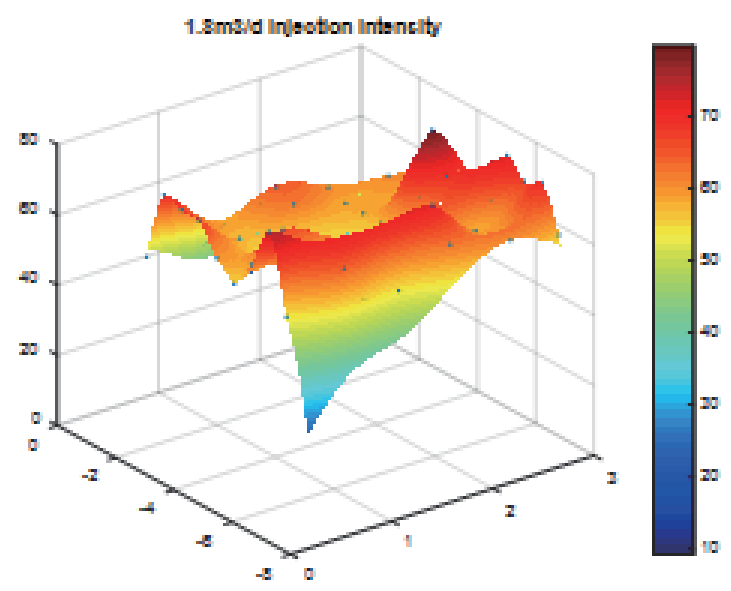

(c)

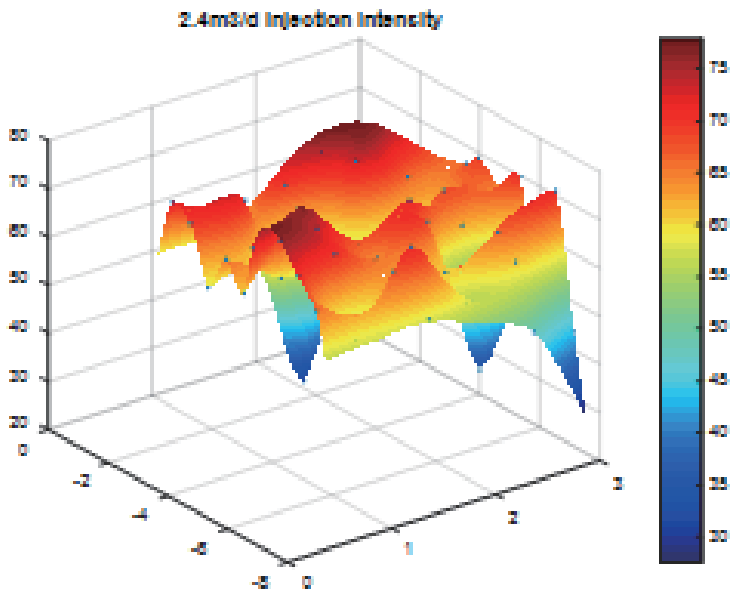

(b)

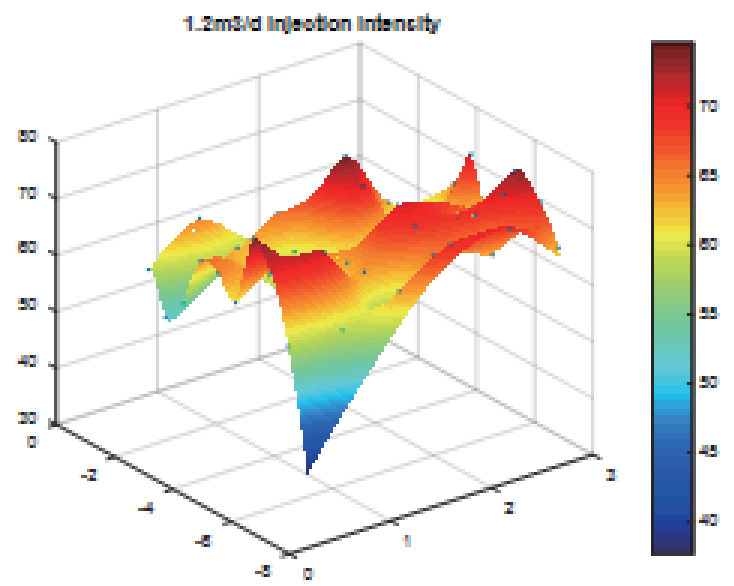

(d)

Fig. 6. (Color online) Steady filtration cloud pictures for different injection intensities. (a) $3 \mathrm{~m}^{3} / \mathrm{d}$. (b) $2.4 \mathrm{~m}^{3} / \mathrm{d}$. (c) $1.8 \mathrm{~m}^{3} / \mathrm{d}$. (d) $1.2 \mathrm{~m}^{3} / \mathrm{d}$.

intensity and the amplitude also increases. For the different profiles or in the preferential flow channel, the rates of decrease of both the saturation and distribution characteristics are different. The distribution laws are complex and cannot be described by a single law. Under the same injection intensity, there are also large differences in the preferential flow profile between different rare-earth ores. We also found that when the injection intensity is large, shallow preferential flows are more numerous than deeper preferential flows; when the injection intensity is small, preferential flow usually occurs at the bottom. Because of the measurement error of the test sensors and the disturbance of the soil embedding the sensor, the shape of the saturation contour in the cloud pictures is not regular. Compared with the distribution law of saturation, the distribution of the preferential flow has greater variability and uncertainty. 


\section{Conclusions}

We monitored the water content of a rare-earth ore at all measuring points with multiple moisture sensors and Brilliant Blue FCF (C.I. 42090) in a dye tracer experiment designed to investigate and quantify the preferential flow. We obtained the following conclusions.

(1) The dyeing area ratio and dying depth reflect the degree of preferential flow in the soil. The dyeing area ratio is related to the ratio of macropores participating in the preferential flow. The larger the dyeing area ratio, the greater the preferential flow. Generally the dyeing area ratio of the preferential flow region follows the law of "strong-weak-stronger-weak-none" with increasing depth of the rare-earth ore; however, it was observed from a single profile that in some local regions, the dyeing area fraction increased with increasing depth of the rare-earth ore, suggesting that water flow could infiltrate continuously while bypassing the rare-earth ore region, which is difficult to pass.

(2) It was also found that the higher the average water content of the profile, the greater the preferential flow, although the relationship was nonlinear. The analysis of the results of field and indoor experiments and real-time monitoring showed that the higher the infiltration intensity, the greater the preferential flow in the soil, and the higher the initial water content in the soil, the more abundant the preferential flow generated, but they are not directly proportional. At the same time, when the injection intensity is low, there is no preferential flow in the soil with large pores. This was caused by the unevenness of the texture distribution of the rare-earth ore. However, even in a homogeneous rare-earth ore, nonlinearity (or instability) of the flow could also cause preferential flow; moreover, preferential flow can occur in different dimensions.

(3) Although there are numerous methods of studying preferential flow, they all have disadvantages. The dyeing method is intuitive but is destructive and unrepeatable. Although indoor column experiments enable quantitative and repeatable testing, the significance of the results is reduced by the destruction of undisturbed soil; moreover, when the soil originates far from the laboratory, the cost of acquiring the soil will increase. It is difficult to use computer tomography to detect preferential flow because of the cost and instrumental problems. A comprehensive field experiment is thus very important. To study preferential flow qualitatively and quantitatively, the accumulation of a large amount of experimental data and the development of convenient observation technology are required. Although a single method might have partial success in solving some problems in the field of preferential flow, ideal research results and objectives will usually require the combination of various methods. Moreover, indoor experiments and outdoor experiments must be closely coordinated to explore the mechanism of preferential flow. Considerable labor, materials, and time are required to carry out field and indoor experiments and real-time monitoring of preferential flow to obtain significant data and conclusions. 


\section{Acknowledgments}

This research was funded by the Project of Ningde Normal University (No. 2017ZDK05) and Ningde Normal University Special Funding Research Project (No. 2019ZX408). The authors appreciate the valuable comments and suggestions from the editors and reviewers.

\section{References}

1 M. H. Larsson, N. J. Jarvis, and G. Torstensson: J. Hydrol. 215 (1999) 116. https://doi.org/116.10.1016/S00221694(98)00265-0

2 S. D. Prima, R. Marrosu, and L. Lassabatere: J. Hydrol. 563 (2018) 633. https://doi.org/10.1016/j. jhydrol.2018.06.033

3 M. Mossadeghi-Björklund, J. Arvidsson, T. Keller, J. Koestel, M. Lamandé, M. Larsbo, and N. Jarvis: Soil Tillage Res. 156 (2016) 91. https://doi.org/10.1016/j.still.2015.09.013

4 F. Sheng, L. Y. Zhang, and D. Wu: Trans. Chin. Soc. Agric. Eng. 32 (2016) 1 (in Chinese). https://doi. org/10.11975/j.issn.1002-6819.2016.06.001

5 C. J. Guo, J. Z. Liu, and J. G. Sun: J. Soil Water Conserv. 26 (2012) 41. http://en.cnki.com.cn/Article en/ CJFDTotal-TRQS201206010.htm

6 H. H. Liu, C. Doughty, and G. S. Bodvarsson: Water Resour. 34 (1998) 633. https://doi.org/10.1029/98WR02040

7 Z. D. Wu and Q. J. Wang: Trans. Chin. Soc. Agric. Mach. 1 (2010) 53. https://doi.org/10.3969/j.issn.10001298.2010.Supp.011

8 C. Zeng, Q. J. Wang, and J. Fan: Trans. CSAE 26 (2010) 24 (in Chinese). https://doi.org/10.3969/j.issn.10026819.2010.01.005

9 D. J. Cheng,L. J. Wang,Y. K. Hou, and Y. Fang: Water Resour. Hydropower Technol. 43 (2012) 7. https://doi. org/10.1109/ICACI.2012.6463307

10 B. W. Zhang and M. A. Shao: Trans. CSAE 26 (2010) 9. https://doi.org/10.3969/j.issn.1002-6819.2010.03.002

11 A. B. Tobella, H. Reese, A. Almaw, J. Bayala, A. Malmer, H. Laudon, and U. Ilstedt: Water Resour. Res. 30 (2014) 3342. https://doi.org/10.1002/2013WR015197

12 F. Sheng and Y. Fang: Soils 44 (2012) 144.https://www.oalib.com/paper/1420810

13 I. Forrer, A. Parrita, and R. Kasteel: Eur. J. Soil Sci. 51 (2000) 313. https://doi.org/10.1046/j.13652389.2000.00315.x

14 D. Dtadler, M. Stahli, and P. Aeby: Am. J. Soil Sci. Soc. 64 (2000) 505.

15 J. Feng and Z. C. Hao: Adv. Water Sci. 13 (2002) 611. http://en.cnki.com.cn/Article_en/CJFDTOTALSKXJ200205013.htm

16 L. Luo and H. Lin: Vadose Zone J. 8 (2009) 233.https://doi.org/10.2136/vzj2008.0010

17 P. C. Baveye, M. Laba, W. Otten, and L. Bouckaert: Geoderma 157 (2010) 51. https://doi.org/10.1016/j. geoderma.2010.03.015

18 S. H. Luo, T. Luo, G. S. Wang, J. Liu, S. L. Hu, and D. M. Zhu: Soils 50 (2018) 421. http://en.cnki.com.cn/ Article en/CJFDTOTAL-TURA201802028.htm

19 G. S. Wang, Y. M. Lai, P. Long, S. L. Hu, B. G. Hong, and Y. Gui: Chin. J. Geotech. Eng. 40 (2018) 910. https:// doi.org/10.11779/CJGE201805016

20 S. L. Zhang and X. S. Liu: Microelectron. Reliab. 93 (2019) 115. https://doi.org/10.1016/j.microrel.2019.01.009 